\title{
Multiple Hereditary Exostoses
}

\author{
Carolyn M. Sofka, MD • Gregory R. Saboeiro, MD • Robert Schneider, MD
}

(C) Hospital for Special Surgery 2005

\section{History}

This is a case of a 50-year-old male with worsening pain over the past 8 years in both the right upper extremity and right lower extremity. The patient, of note, did not have any neck pain. On clinical examination, there was mild right upper extremity weakness (4/5) and abnormal reflexes in the right upper extremity and right lower extremity. There was mild right lower extremity weakness.

Given the neurologic symptoms, radiographs were obtained, including imaging of the axial skeleton.

\section{Radiologic findings}

Multiple imaging studies were obtained. Some of the initial imaging studies obtained were radiographs of the spine. Lateral radiograph of the cervical spine demonstrated a large exostosis involving the posterior elements at the $\mathrm{C} 2-3$ level (Fig. 1). Additional radiographs of the chest and spine demonstrated additional sessile osseous exostoses involving the proximal left humerus and right scapula (Figs. 2 and 3).

Additional imaging of the cervical spine was obtained to better evaluate the large ossific mass involving the posterior elements at $\mathrm{C} 2-3$. Sagittal reformatted and axial computed tomography (CT) images demonstrated a large, expansile, osseous lesion involving the posterior elements, with marked narrowing of the central canal (Fig. 4). Magnetic resonance (MR) imaging demonstrated marked compression on the spinal cord as seen on both the sagittal and axial images, with focal linear intrasubstance cord

C.M. Sofka, MD ( $\bowtie) \cdot$ G.R. Saboeiro, MD • R. Schneider, MD Department of Radiology and Imaging,

Hospital for Special Surgery,

535 East 70th Street, New York, NY 10021, USA

e-mail: sofkac@hss.edu

\section{C.M. Sofka, MD}

Weill Medical Center of Cornell University,

New York, NY 10021, USA signal hyperintensity consistent with myelomalacia and cord atrophy (Fig. 5).

The diagnosis was multiple hereditary exostoses with expansile osteochondroma at C2-3 with resultant marked cord compression and cord atrophy and myelomalacia.

\section{Discussion}

Hereditary multiple exostosis is a rare disorder characterized by multiple osteochondromas with the associated potential of malignant degeneration. A possible genetic mutation (EXT gene) was postulated as a cause of he-

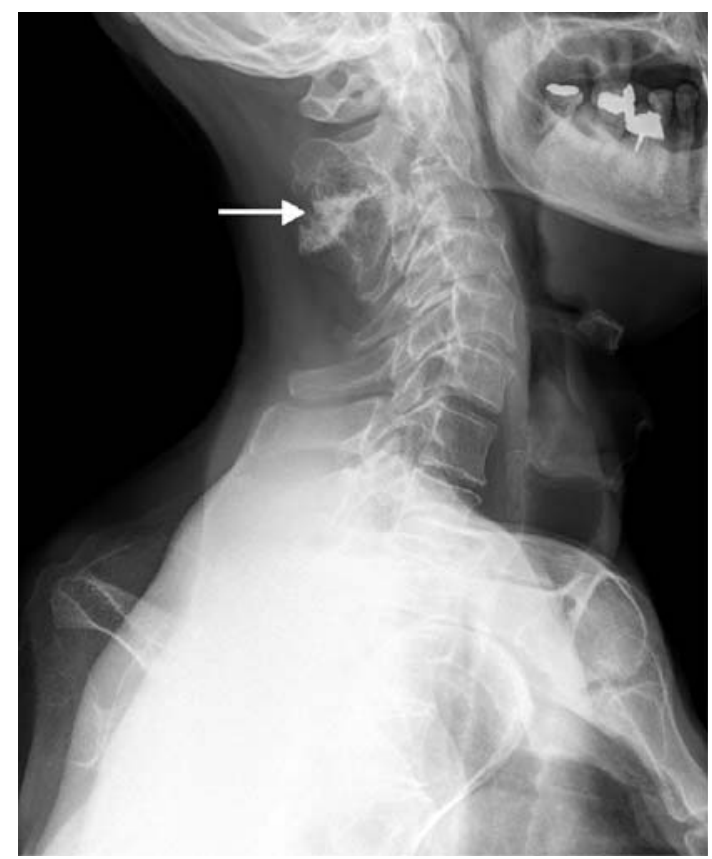

Fig. 1. Lateral radiograph of the cervical spine demonstrating a large, exophytic, osseous mass involving the posterior elements at the C2-3 level (arrow) 


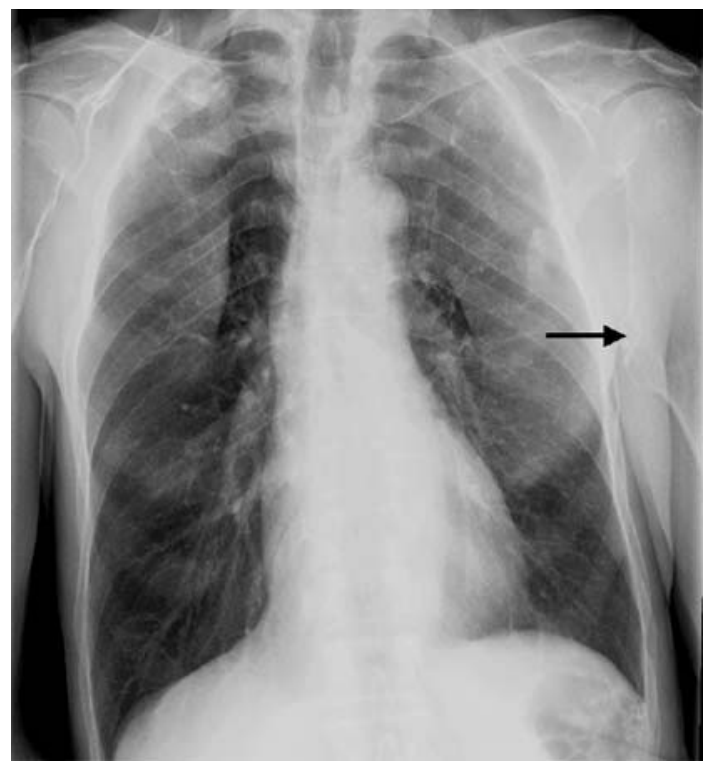

Fig. 2. Posteroanterior view of the chest demonstrates a broad-based sessile osteochondroma involving the proximal left humerus (arrow) reditary osteochondromas and may be used to identify markers for potential malignant degeneration [1].

Osteochondromas in the axial skeleton are unusual, and reports in the literature primarily consist of isolated case reports [2-8]. Cases involving the $\mathrm{C} 1$ and $\mathrm{C} 2$ levels resulting in cord compression were described in limited series case reports as well as myelopathy from an osteochondroma involving the C5 lamina $[4,5,7]$.

Malignant transformation is seen in $3 \%$ to $5 \%$ of patients with hereditary multiple exostosis [8]. Imaging of osteochondromas can provide information about the size and location of the lesions, for determination of malignant potential as well as for preoperative planning, with mapping of the relationship of the lesion to adjacent neurovascular structures. Magnetic resonance imaging, with its superior soft tissue contrast, can identify the morphology of the cartilaginous cap of the osteochondromas and potentially associated soft tissue masses, suggesting malignant transformation [9]. Nuclear medicine bone scan is useful to identify additional lesions throughout the skeleton and CT can accurately identify the regional osseous anatomy and potential fractures through exophytic lesions.
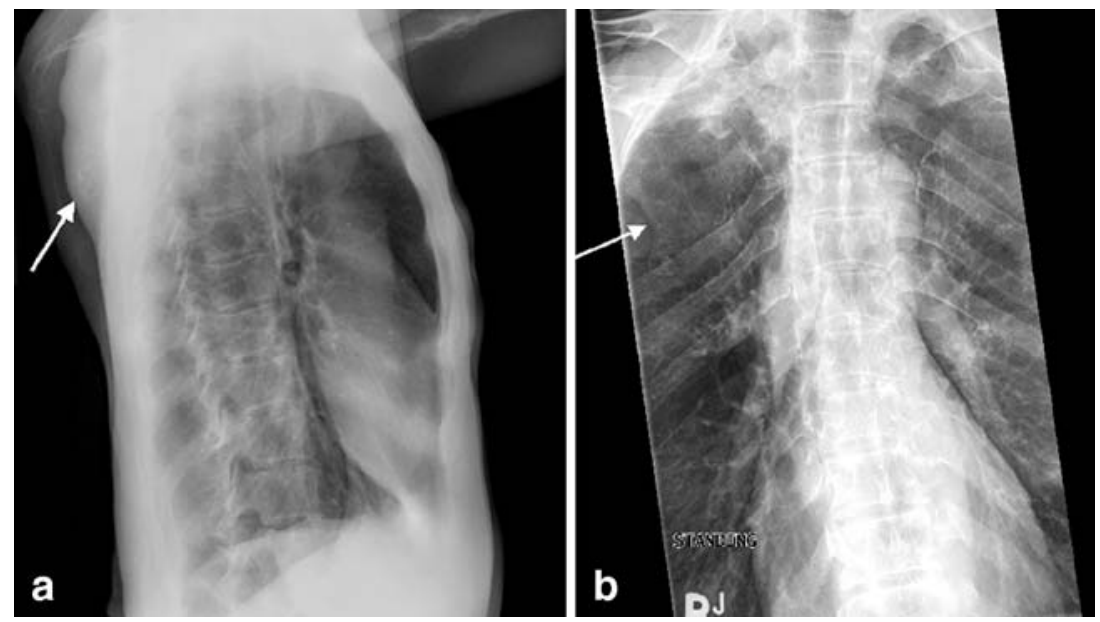

Fig. 3. Lateral (a) and anteroposterior (b) views of the thoracic spine demonstrate an expansile osteochondroma arising from the right scapula (arrows)

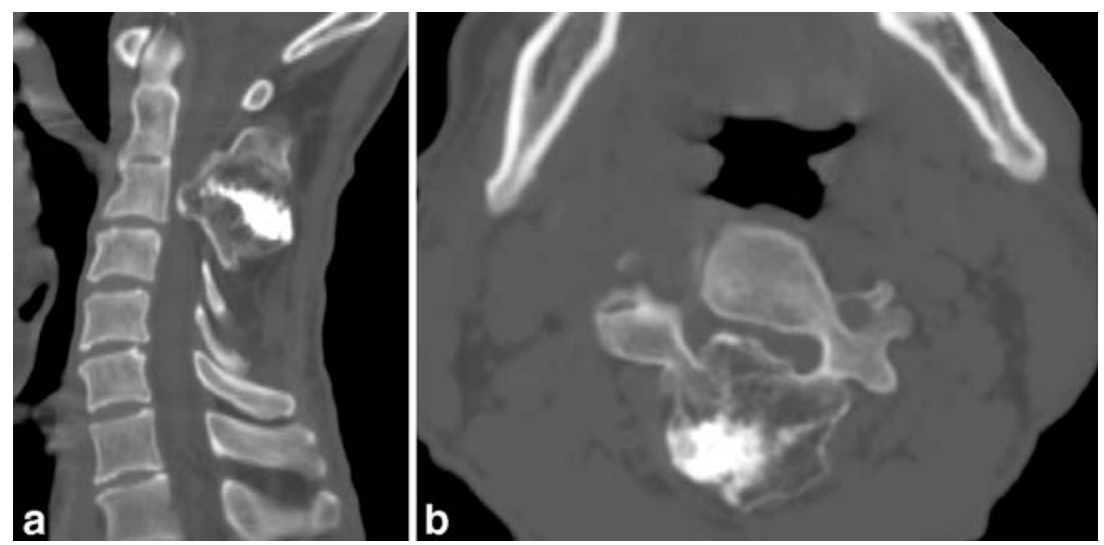

Fig. 4. Sagittal reformatted (a) and axial (b) CT images of the cervical spine demonstrate a large expansile osteochondroma involving the posterior elements at $\mathrm{C} 2-3$. On sagittal examination, note the congenital fusion of the $\mathrm{C} 2-3$ vertebral bodies. Axial image demonstrates the marked cord compression from the osteochondroma 

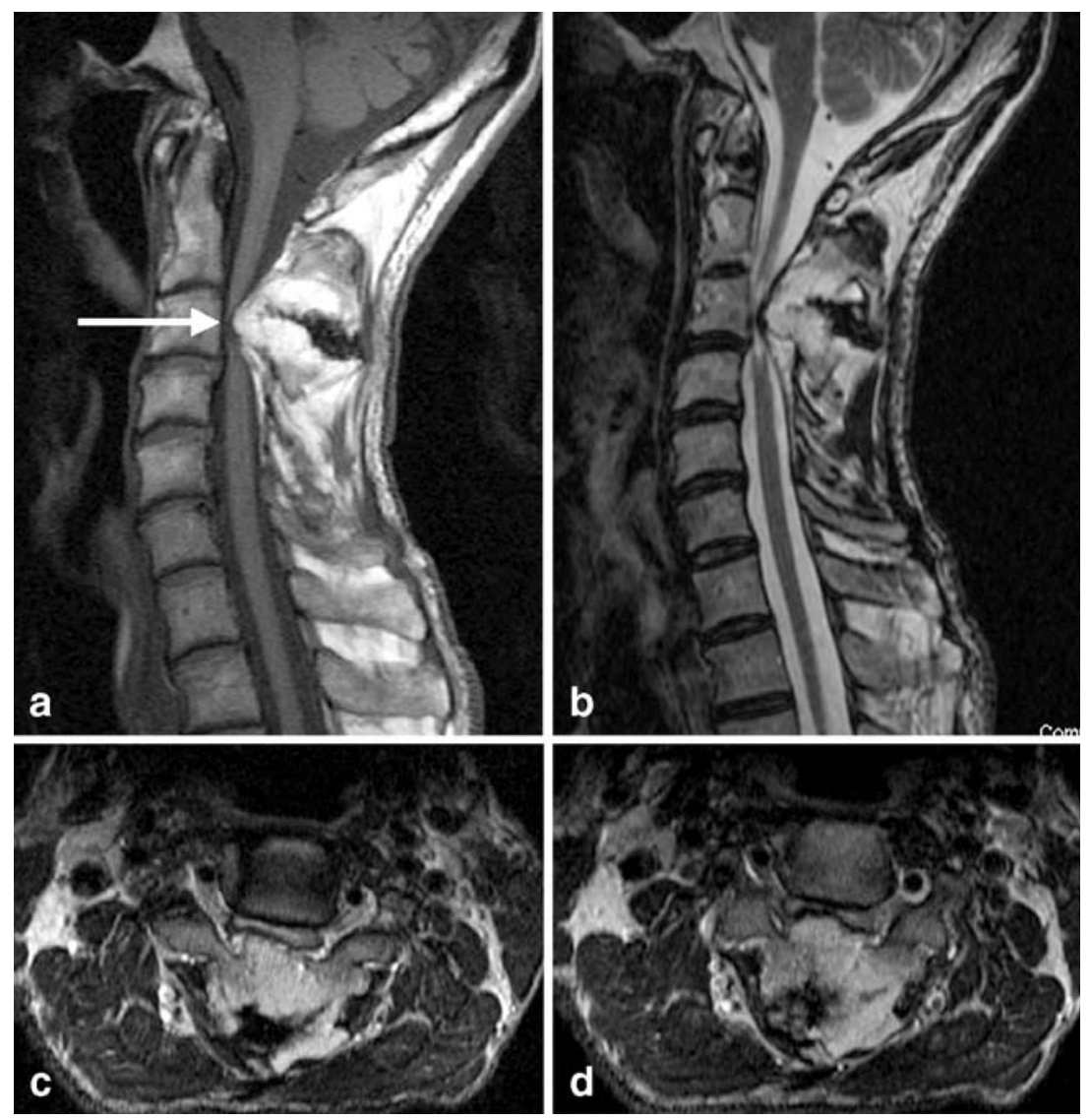

Fig. 5. Sagittal T1 (a) and T2 (b) weighted MR images of the cervical spine demonstrate the marked narrowing of the spinal canal at the C3 level. At the compressed level, the axial T2 (c, d) weighted images demonstrate marked narrowing of the cord with intrasubstance cord signal consistent with myelomalacia

Acknowledgments The authors would like to thank Dr. Russell Huang for providing much of the clinical information.

\section{References}

1. Pierz KA, Stieber JR, Kusumi K, Dormans JP (2002) Hereditary multiple exostoses: One center's experience and review of etiology. Clin Ortop 401:49-59

2. Mikawa Y, Watanabe R, Nakashima Y, Hayashida T (1997) Cervical spinal cord compression in hereditary multiple exostosis: Report of a case and a review of the literature. Arch Orthop Trauma Surg 116(1-2):112-115

3. Eder HG, Oberbauer RW, Ranner G (1993) Cervical cord compression in hereditary multiple exostoses. J Neurosurg Sci 37(1):53-56

4. Chooi YS, Siow YS, Chong CS (2005) Cervical myelopathy caused by an exostosis of the posterior arch of $\mathrm{C} 1$. J Bone Joint Surg Br 87(2):257-259
5. Korinth MC, Ramaekers VT, Rohde V (2004) Cervical cord exostosis compressing the axis in a boy with hereditary multiple exostoses. Case illustration. J Neurosurg Spine 100(2):223

6. Ohtori S, Yamagata M, Hanaoka E, Suzuki H, Takahashi K, Sameda H, Moriya H (2003) Osteochondroma in the lumbar spinal canal causing sciatic pain: report of two cases. J Orthop Sci 8(1):112-115

7. Ratliff J and Voorhies R (2000) Osteochondroma of the C5 lamina with cord compression: case report and review of the literature. Spine 25(10):1293-1295

8. Mermer MJ, Gupta MC, Salamon PB, Benson DR (2002) Thoracic vertebral body exostosis as a cause of myelopathy in a patient with hereditary multiple exostoses. J Spinal Disord Tech 15(2):144-148

9. Murphey MD, Choi JJ, Kransdorf MJ, Flemming DJ, Gannon FH (2000) Imaging of osteochondroma: variants and complications with radiologic-pathologic correlation. Radiographics 20(5):1407-1434 